\title{
An empirical assessment of the extended service quality model
}

\author{
Deon Nel \\ Graduate School of Business, University of Cape Town, Breakwater Campus, Cape Town, 8000 Republic of South Africa \\ Christo Boshoff* \\ Department of Business Management, University of Port Elizabeth, P.O. Box 1600, Port Elizabeth, 6000 Republic of South Africa \\ Gerhard Mels \\ Department of Mathematical Statistics, University of Port Elizabeth, P.O. Box 1600, Port Elizabeth, 6000 Republic of South Africa
}

Received May 1997

\begin{abstract}
The purpose of this article is to conduct an empirical assessment of the extended service quality model proposed by Zeithaml, Berry \& Parasuraman. The article provides a brief review of the gap concept as a measurement framework for service quality issues. This is followed by a description of the relationships in the extended service quality model and bow it can be tested. The assessment consists of three steps. First, the internal consistency and the discriminant validity of the scales used to measure the latent variables of the extended service quality model are investigated. Based on these results an amended service quality model is fitted to the data. Finally, a revised structure for a more appropriate service quality model is suggested based on a structural equation assessment of an amended service quality model. The questionnaire was mailed to a total of 10000 customers of a large national electricity utility in the United Kingdom. The total was divided into 5000 each for business and domestic customers, which was again subdivided into 2500 active users and 2500 inactive users of the company's services. After elimination of incomplete questionnaires, a total of 1860 questionnaires were used in the analysis, an effective response rate of $18.6 \%$. The empirical results reported in this study suggest that considerable research is still required to enhance our understanding of the factors influencing service quality. Three concerns are the improvement of the psychometric capabilities of the scales used in this study, the search for unspecified constructs and antecedents which may influence individual gaps, and the unbundling of the internal gaps.
\end{abstract}

*Author to whom correspondence should be addressed.

\section{Introduction}

The construct service quality has been the focus of many scholarly studies (Lehtinen \& Lehtinen, 1983; Lewis \& Booms, 1983; Parasuraman, Zeithaml \& Berry, 1985; Bolten \& Drew, 1991; Cronin \& Taylor, 1992; Teas, 1993). Since 1985 , most of the debate has centred around the conceptualization and measurement of service quality based on the gap theory stream of research (Parasuraman, Zeithaml \& Berry, 1985; Zeithaml, Berry \& Parasuraman, 1988; Zeithaml, Parasuraman \& Berry, 1990; Zeithaml, Berry \& Parasuraman, 1993). The SERVQUAL instrument (Parasuraman, Zeithaml \& Berry, 1988) has sparked a proliferation of SERVQUAL-based studies (Crompton \& Mackay, 1989; Johnson, Dotson \& Dunlap, 1988; Woodside, Frey \& Daly, 1989) with some studies questioning the scale's reliability and validity (Carman, 1990; Babakus \& Boller, 1992; Finn \& Lamb, 1991). These concerns resulted in a refinement and reassessment of the scale (Parasuraman, Berry \& Zeithaml, 1991) but recent criticism has further questioned the difference-score conceptualization of the SERVQUAL instrument (Cronin \& Taylor, 1992; Brown, Churchill \& Peter, 1993; Teas, 1993). In response to these criticisms it was suggested that current empirical evidence does not indicate superiority for the non-difference score conceptualization (Parasuraman, Berry \& Zeithaml, 1993). Minor psychometric concerns did not outweigh the benefits of more accurate diagnostic information provided by measuring two levels of expectations - adequate and desired, and comparing that to customer perceptions (Zeithaml, Berry \& Parasuraman, 1993).
It is evident from the literature that most of the empirical work had been focussed on the gap 5 perception-minus-expectations framework as operationalized by Parasuraman, Berry \& Zeithaml (1985). However, the management of service quality concerns wider issues of organizational structure, philosophy and culture that can also influence service delivery and ultimately customer perceptions of service quality (Bowen \& Schneider, 1988; Gronroös, 1984; Heskett, 1987). The discrepancy between expectations and perceptions are reported to be caused by a series of organizational behavioural factors. The organizational shortcomings lead to four internal gaps, which, in turn, lead to the service gap as perceived by customers (Zeithaml, Berry \& Parasuraman, 1988). The relationships in the extended service quality model were tested empirically by six propositions pertaining to antecedents influencing the internal gaps. The results found only partial support for the six propositions and highlighted the need for further refinement of scales relating to antecedents factors (Parasuraman, Berry \& Zeithaml, 1990).

The purpose of this article is to conduct an empirical assessment of the extended service quality model proposed by Zeithaml, Berry \& Parasuraman (1988). The assessment consists of three steps. First, the internal consistency and the discriminant validity of the scales used to measure the latent variables of the extended service quality model are investigated. Based on these results an amended service quality model is fitted to the data. Finally, a revised structure for a more appropriate service quality model is suggested.

The article provides a brief review of the gap concept as a measurement framework for service quality issues. Next is a description of the study in which the relationshios in the 
extended service quality model are tested. It is followed by the scale refinement results which are used to conduct a structural equation assessment of an amended service quality model. Due to the poor fit of this amended model a more appropriate service quality model for the samples of this study is proposed and fitted to the data. Finally, managerial implications, recommendations for future research and conclusions, illustrate the shortcomings of the model in its current form.

\section{Theoretical background}

In applying a service quality measurement process, the welldocumented 'Gaps' Model (Parasuraman, Zeithaml \& Berry, 1985) serves as a conceptual framework for understanding service quality delivery. The model views service quality as five potential gaps where areas of service quality shortcomings can occur. The identification of various gaps and the resultant model emanated from a series of customer focus groups and in-depth executive interviews on issues relating to service quality. The conceptual model defines service quality from the customer's viewpoint and from the marketer of services' point of view. From the customer's standpoint ten determinants of service quality were identified. Later empirical testing on the customer side of the model consolidated the determinants into five dimensions, namely: tangibles; reliability; responsiveness; assurance; and empathy. The SERVQUAL instrument focusses on measuring customer perceptions of service quality along these five dimensions, known as gap 5 in the model. The serviceprovider side of the model provides a set of constructs that could affect the delivery of service quality (Zeithaml, Berry \& Parasuraman, 1988). These constructs are listed in Table 1. The result was a detailed conceptual explication of the extended service quality model that was used to develop measures of the internal organizational gaps (Zeithaml, Parasuraman \& Berry, 1990).

\section{Extended model}

The extended model of service quality in Figure 1 depicts the communication and control processes to manage employees in the organization and the consequences of these processes. The internal organizational gaps which can impede the delivery of service quality that consumers perceive to be of high quality, are:

Gap 1: Difference between consumer expectations and management perceptions of consumer expectations;

Gap 2: Differences between management perceptions of consumer expectations and service quality specifications;

Gap 3: Difference between service quality specifications and the service quality actually delivered; and

Gap 4: Difference between service quality delivery and what is communicated about the service to customers.

Figure 1 illustrates that perceived service quality (gap 5) is a function of the magnitude and direction of the five dimensions, as well as a set of constructs related to each internal gap. To test the extended model as a theory, measures of the constructs were conceptualized by Zeithaml, Berry \& Parasuraman (1988) and operationalized by Parasuraman, Berry \& Zeithaml (1990). Table 1 lists the constructs hypothesized
Table 1 Hypothesized antecedents of the internal service quality gaps (Parasuraman, Berry \& Zeithaml, 1990)

\section{Gap 1 Antecedents}

Marketing research orientation: Extent to which managers make an effort to understand customers' needs and expectations through formal and informal information-gathering activities.

Upward communication: Extent to which top management seeks, stimulates and facilitates the flow of information from employees at lower levels.

Levels of management: Number of managerial levels between top and bottom levels.

\section{Gap 2 Antecedents}

Management commitment to service quality: Extent to which management views quality service as a strategic goal and allocates adequate resources to it.

Goal setting: Existence of a formal process for setting service quality goals.

Task standardization: Extent to which technology and training are used to standardize service tasks.

Perceptions of feasibility: Extent to which managers believe that customers' expectations can be met.

\section{Gap 3 Antecedents}

Teamwork: Extent to which all employees pull together to reach a common goal.

Employee-job fit: Match between the skills of employees and their jobs.

Technology-job fit: The appropriateness of the tools and technology employees use in their jobs.

Perceived control: Extent to which employees perceive that they are in control of their jobs and can act flexibly.

Supervisory control systems: The extent to which employees are evaluated on and compensated for what they do rather than solely on the quantity of their output.

Role conflict: Extent to which employees perceive that they cannot satisfy all the demands of all their internal and external customers.

Role ambiguity: Extent to which employees are uncertain about what managers and supervisors expect from them and how to satisfy those expectations.

\section{Gap 4 Antecedents}

Horizonsal communication: Extent to which communication and coordination occur among the departments that serve customers.

Propensity to overpromise: Extent to which the firm feels pressure to promise more than it can deliver.

to influence perceived service quality. The testing of the extended model has been the focus of at least one published empirical study by Parasuraman. Berry \& Zeithaml (1990). Customers, employees and management of five service companies were researched. Six propositions were tested as implied by the model. Four of the six dealt with the antecedents influencing the internal gaps as discussed in Zeithaml, Berry \& Parasuraman (1988). The fifth proposed that the size of the gap 5 discrepancy is related to the size of the internal gaps. The sixth tested the validity of the five dimensions as a valid measure of customers' overall evaluations of service quality. 


\section{GAP 1}

Levels of

Management

Management Commitment
to Service Quality
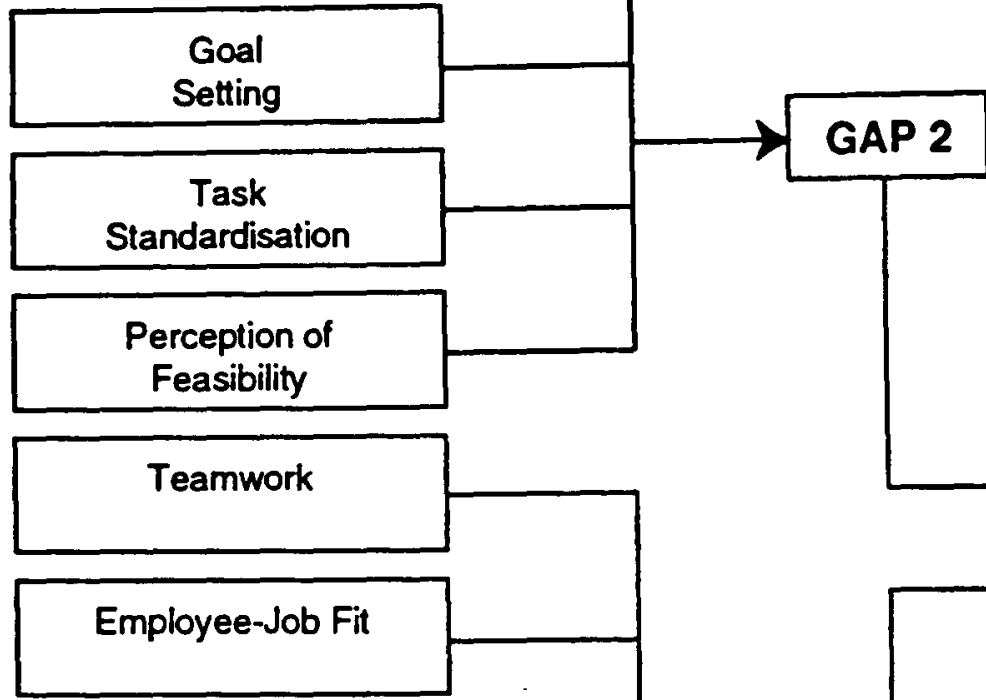

\section{Technology-Job Fit}

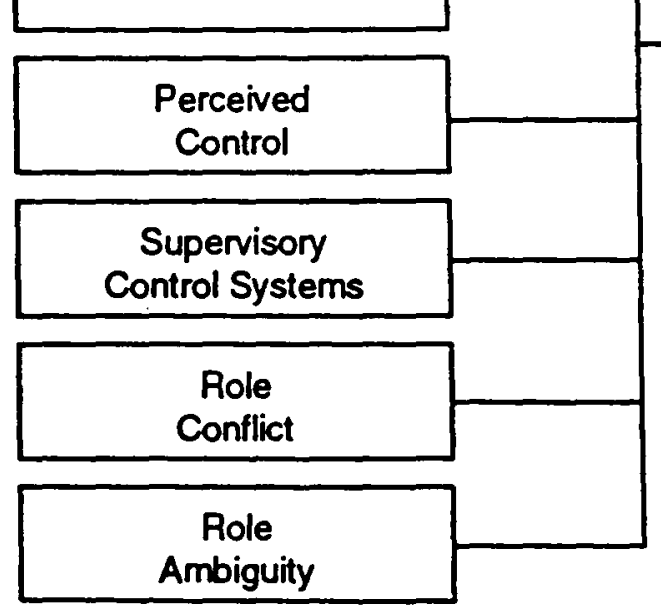

\section{GAP 3}

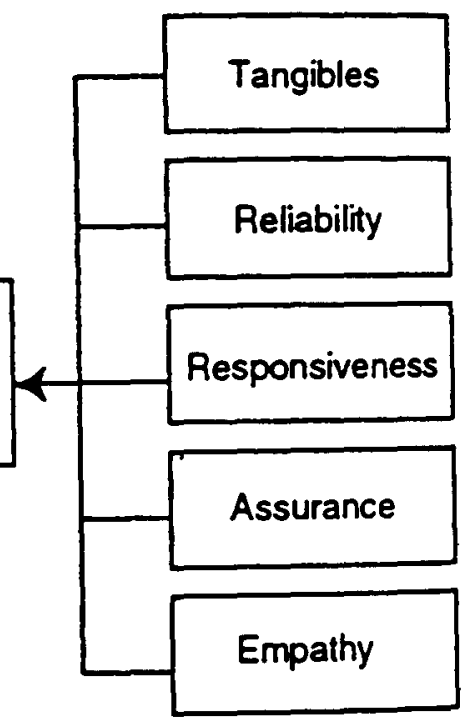

Horisontal

Communication

\section{Propensity to \\ Overpromise}

\section{GAP 4}

Figure 1 Extended model of service quality (Zeithaml, Berry \& Parasuraman, 1988)

The measurements of the service quality gap (gap 5) uses the 22 expectation and performance items from the SERVQUAL scale (Parasuraman, Zeithaml \& Berry, 1988). The measurement of gap 1 is different from the other gaps since it crosses the boundary between the customer and the service provider in the conceptual model of service quality. The 
extent of gap 1 is measured by determining the discrepancy between managers' ratings and customers' ratings on the expectations battery of items on the SERVQUAL scale.

Gaps 2 to 4 allow for a direct measure of the service standards gap, service delivery gap and the communications gap, respectively. In addition to the direct measures of the gaps, respondents complete a battery of multiple-item questionnaires covering the antecedents of gaps 1 to 4 . The antecedents are derived from organizational constructs hypothesized to be responsible for driving the internal gaps (Zeithaml, Berry \& Parasuraman, 1988).

Parasuraman et al. (1990) empirically validated the extended service quality model in 1990 . The results indicated that the Cronbach alpha coefficients (Cronbach, 1951) for the scales designed to measure the internal gaps were in many cases unstable and low. The regression results found only partial support for the six propositions tested (Parasuraman, Berry \& Zeithaml, 1990). The varied results could be ascribed to the absence of proper reliability assessment and analyses such as an exploratory factor analysis and limited scale refinement of the hypothesized constructs. To date no published research have attempted to conduct further empirical testing and refinement of the scales to test the stability of the model. A second explication is the use of regression analyses by Parasuraman et al. (1990) to analyse the data. It is possible to use a maximum likelihood approach to test the theoretical model, which would permit measurement error and structural relations for the model to be estimated simultaneously. Although the facility is available on computer programmes such as LISREL and RAMONA this analysis technique was not used by Parasuraman et al. (1990). Instead multiple regression analyses and analysis of variance procedures were used to test the relevant hypotheses. There are disadvantages to using regression analyses procedures instead of a structural equation analysis procedure. For instance, it ignores potential relationships among independent variables, and it disregards errors of measurement.

A regression analysis considers the influence of one indepenedent variable on a dependent variable while keeping the influence of the other independent variables constant. It does not consider the possible interrelationships among independent variables - something structural equation modelling can do (Pollay \& Mittal, 1993). This study overcomes this limitation of the only previous attempt to empirically test the extended service quality model by using a structural equation modelling approach to assess the validity of the model.

\section{Methodology \\ Sample}

The gap 5, or SERVQUAL questionnaire, was mailed to a total of 10000 customers of a large national electricity utility in the United Kingdom. Expectations and perceptions of service experiences were measured simultaneously on the same questionnaire. The total was divided into 5000 each for business and domestic customers, which was again subdivided into 2500 active users and 2500 inactive users of the company's services. Respondents who had not used services in the past five years were classified as inactive users.

A total of 2986 questionnaires were returned by the cut-off date, resulting in a response rate of $26.9 \%$. After elimination of incomplete questionnaires, a total of 1860 questionnaires were used in the analysis, an effective response rate of $18.6 \%$. Within the four categories the completed questionnaires used were as follows: (1) business users $n=495$; (2) business nonusers $n=79$; (3) domestic users $n=1047$; and (4) domestic non-users $n=239$.

Managers and other staff within the company were required to complete the gaps 1 to 4 questionnaires. Anonymity was assured. A total of 158 out of 500 responded by the cut-off date, for a response rate of $32 \%$.

\section{Data analysis procedures}

From the 1860 consumer respondents a random sample of 158 were selected to be paired with the 158 respondents in the employee sample to provide data points for the statistical analyses. The pairing was necessary to compare the expectations battery of the customer sample with the perceptions of the internal employees about customer expectations.

To evaluate the structural relationships in the extended service quality model proposed by Parasuraman, Berry \& Zeithaml (1990), the data analysis was classified into four phases or stages. Phase one deals with the reliability of the latent variables of the extended model, while phase two is concerned with the discriminant validity of the measurements of these latent variables for the sample used in the present study. The third phase of the data analysis fits the extended service quality model (modified according to the results obtained from phase one and two) to the observed data. The fourth and final phase investigates the feasibility of providing a more appropriate extended service quality model for the samples of this study.

The reliability and discriminant validity analyses of the latent variables included in the extended service quality model were conducted separately for the antecedents of the respective gaps: gap 1 (employee versus customer expectations), gaps 2 to 4 (employee sample), and gap 5 (perceptions versus expectations for the customer sample). In all four instances the internal consistency of the proposed measuring instruments were evaluated by calculating Cronbach alpha coefficients. Where necessary, individual items were deleted from the scales to increase coefficients. Exploratory factor analysis was used to assess the discriminant validity of the amended scales consisting of the remaining items. If the discriminant validity of an instrument(s) could not be established empirically, the corresponding latent variable(s) was deleted from the original extended service quality model. Where an item(s) was deleted from a scale(s), the Cronbach alpha coefficient(s) was recalculated. If the alpha value was considered unacceptable, the corresponding latent variable was removed from the model depicted in Figure 1. The results obtained from these analysis procedures led to the amended service quality model which is presented in Figure 2 by means of a path diagram (Bollen, 1989). Path analysis with latent variables was employed to conduct a structural equation assessment of this model and to investigate the existence of a more appropriate structural equation model for service quality.

\section{Scale refinement: gap measures and antecedents}

During the initial phase of data analysis the internal consistency of the instruments measuring each of the antecedents 
were evaluated by means of Cronbach alpha coefficients. Table 2 shows that the initial values were generally low. For scales with alpha coefficients lower than 0.5 the successive deletion of individual items from the scales resulted in considerable improvements. The exceptions being 'management commitment to service quality; (MCON), 'employee/job fit' (JOBF), 'supervisory control' (SUPCONT), 'horizontal communication' (HCOM), and 'propensity to overpromise' (PPROM). Due to their low internal consistencies these antecedents were eliminated from the original model (see Figure 2). Note that although the antecedents of gap 4 were removed from the model at this early stage, gap 4 itself was retained as its influence on gap 5 could still be evaluated.

The remaining instruments revealed reasonably high internal reliability - at least above the 0.5 level Nunnally (1978) regards as the minimum for basic research.

The next step was to factor analyse the items which are regarded as measures of the remaining antecedents believed to cause individual service quality gaps (Zeithaml, Berry \& Parasuraman, 1988). Separate factor analyses were performed for the antecedents of gaps 1 and 2 and for those of gap 3. The computer programme BMDP4M (Frane, Jennrich \& Sampson, 1990) was used for this purpose by specifying principal factor analysis as the method for initial factor extraction and a Direct Quartimin oblique rotation of the original factor matrix (Jennrich \& Sampson, 1966).

The resulting rotated factor matrix for the antecedents of gaps 1 and 2 is shown in Table 3. Respondents interpreted all five antecedents as separate constructs, and items that remained after the assessment of internal consistency could be regarded as measures of the various constructs. 'Marketing research information' is measured by $\mathrm{MRO} 1$ and MRO3, while UCOM1 and UCOM3 are measures of 'upward communication', GOALl and GOAL2 of 'goal setting', TASK1 and TASK2 of 'task standardization' and FEAS 1 and FEAS3 are measures of 'perceptions of infeasibility'.

Table 2 Cronbach alpha coefficients of measuring instruments of the latent variables of the extended service quality model

\begin{tabular}{lcc}
\hline Antecedentmeasuring instrument & $\begin{array}{c}\text { Initial } \\
\text { alpha }\end{array}$ & $\begin{array}{c}\text { Final } \\
\text { alpha }\end{array}$ \\
\hline Marketing research orientation (MRO) & 0.35 & 0.74 \\
Upward communication (UCOM) & -0.18 & 0.69 \\
Management commitment to service quality (MCON) & 0.24 & 0.24 \\
Goal setting (GOAL) & 0.79 & 0.79 \\
Task standardization (TASK) & 0.75 & 0.75 \\
Perception of infeasibility (FEAS) & 0.54 & 0.78 \\
Teamwork (TEAM) & 0.80 & 0.80 \\
Employee/job fit (JOBF) & 0.46 & 0.46 \\
Perceived control (PCONT) & 0.36 & 0.56 \\
Supervisory control (SUPCONT) & -0.52 & 0.28 \\
Role conflica (RC) & -0.01 & 0.63 \\
Role ambiguity (RA) & -0.39 & 0.54 \\
Horizontal communication (HCOM) & -0.18 & 0.33 \\
Propensity to overpromise (PPROM) & 0.45 & 0.45 \\
\hline
\end{tabular}

Table 3 Rotated factor loadings: antecedents of gaps 1 and 2

\begin{tabular}{lccccc}
\hline & Factor 1 & Factor 2 & Factor 3 & Factor 4 & Factor 3 \\
\hline & $\begin{array}{c}\text { Goal } \\
\text { setting }\end{array}$ & Feasibility & $\begin{array}{c}\text { Marketing } \\
\text { research } \\
\text { orientation }\end{array}$ & $\begin{array}{c}\text { Upward } \\
\text { communi- } \\
\text { cation }\end{array}$ & $\begin{array}{c}\text { Task } \\
\text { standardi- } \\
\text { zation }\end{array}$ \\
\hline MRO1 & -0.10 & 0.06 & 0.84 & -0.01 & 0.07 \\
MRO3 & 0.13 & -0.04 & 0.68 & 0.05 & -0.05 \\
UCOM1 & -0.01 & 0.09 & 0.07 & 0.62 & -0.01 \\
UCOM3 & -0.01 & -0.07 & -0.03 & 0.81 & 0.03 \\
GOAL1 & 0.63 & -0.01 & 0.11 & -0.13 & 0.11 \\
GOAL2 & 0.93 & 0.06 & -0.07 & 0.01 & -0.01 \\
TASK1 & 0.11 & 0.05 & -0.06 & 0.20 & 0.55 \\
TASK2 & 0.03 & 0.03 & 0.06 & -0.02 & 0.79 \\
FEAS1 & -0.06 & 0.82 & -0.02 & -0.02 & 0.18 \\
FEAS3 & 0.07 & 0.74 & 0.02 & 0.02 & -0.07 \\
\hline
\end{tabular}

The factor analysis for the antecedents of gap 3 produced the matrix of rotated factor loadings listed in Table 4 . This factor structure differs somewhat from the distinct classification of the constructs proposed by Parasuraman, Berry \& Zeithaml (1990). More specifically, both 'role conflict' and 'role ambiguity' items loaded on factor 2. As respondents apparently did not distinguish between these constructs, factor 2 is thus termed 'role stress' and is measured by items RC3, RC4, RA1, and RA2. Role ambiguity and role conflict are considered the two components of role stress (Ramaswani, Agarwal \& Bhargava, 1993: 180-181). An inspection of the questionnaire items measuring 'teamwork' (Zeithaml, Parasuraman \& Berry, 1990: 202) shows that the respondents may have made a distinction between teamwork "with the company' or what we term 'impersonal teamwork' (items 1,2 and 5), and teamwork 'with fellow employees' (items 3 and 4). Table 4 shows that the respondents apparently made the

\begin{tabular}{|c|c|c|c|c|}
\hline & Factor 1 & Factor 2 & Factor 3 & Factor 4 \\
\hline ' & $\begin{array}{l}\text { Impersonal } \\
\text { teamwork }\end{array}$ & $\begin{array}{l}\text { Role } \\
\text { stress }\end{array}$ & $\begin{array}{l}\text { Personal } \\
\text { teamwork }\end{array}$ & $\begin{array}{c}\text { Perceived } \\
\text { control }\end{array}$ \\
\hline TEAM1 & 0.83 & 0.01 & 0.00 & -0.14 \\
\hline TEAM2 & 0.55 & 0.16 & 0.18 & -0.04 \\
\hline TEAM3 & 0.35 & -0.14 & 0.55 & -0.09 \\
\hline TEAM4 & -0.01 & 0.12 & 0.89 & 0.03 \\
\hline TEAM5 & 0.57 & 0.06 & 0.15 & -0.11 \\
\hline PCONT1 & -0.06 & 0.02 & 0.06 & 0.60 \\
\hline PCONT3 & 0.20 & -0.26 & -0.10 & 0.41 \\
\hline PCONT4 & -0.14 & 0.05 & -0.01 & 0.58 \\
\hline RC3 & 0.01 & 0.53 & 0.16 & -0.09 \\
\hline RC4 & 0.24 & 0.57 & 0.16 & 0.13 \\
\hline RAl & 0.21 & 0.66 & -0.02 & 0.12 \\
\hline RA2 & -0.05 & -0.46 & -0.03 & 0.15 \\
\hline RA4 & -0.32 & -0.11 & 0.04 & -0.02 \\
\hline RAS & -0.01 & -0.38 & 0.23 & 0.09 \\
\hline
\end{tabular}


same interpretation as items TEAM1, TEAM2 and TEAM5 loaded on factor 1 while TEAM3 and TEAM4 loaded on factor 3. The fourth factor is identified as the antecedent 'perceiced control' and is measured by items PCONT1, PCONT3 and PCONT4, as expected.

As three 'new' antecedents emerged from this phase of the analysis, the internal consistency of the 'new' measuring instruments had to be (re)calculated. In all three instances acceptable Cronbach alphas were returned ('role stress' 0.73; 'personal teamwork' 0.75; 'impersonal teamwork' 0.80 ).

The results from these two stages of the data analysis are summarized in Table 5 . The table reflects a reduced set of antecedents and a leaner set of items serving as measurements.

\section{Reliability and exploratory factor analysis for gap1}

The Cronbach alpha for the items measuring gap 1 (management perceptions of consumer expectations compared to the actual expectations of consumers) was 0.91 . Various factor solutions (ranging from a two to a five factor solution) were considered. The most interpretable of these was a two factor solution with rotated factor loadings as reported in Table 6. The first factor was labelled 'tangibles' (measured by items EX1, EX2, EX3 and EX4) while the second factor was termed 'human interaction' (measured by items EX5 to EX22).

Reliability and exploratory factor analysis for gaps 2, 3 and 4

The 15 items expected to measure gaps 2,3 and 4 were also factor analyzed. The results suggested that the items intended to measure gap 4 are problematic in the sense that they did not load on a separate factor as expected. As a result gap 4 was removed from the model. A maximum likelihood factor analysis with a Direct Quartimin oblique rotation was then performed for the items intended to measure gaps 2 and 3 .

Table 5 Refined set of antecedents and gaps with their respective measuring items

\begin{tabular}{lll}
\hline Antecedents & Items & Alpha \\
\hline Gap 1 & & 0.74 \\
Market research orientation & MRO1, MRO3 & 0.69 \\
Upward communication & UCOM1, UCOM3 & Not applicable \\
Levels of management & LEV1 & (measured by \\
& & one item) \\
Gap 2 & & \\
Goal setting & & 0.79 \\
Task standardization & TASK1, TASK2 & 0.75 \\
Perception of infeasibility & FEAS1, FEAS3 & 0.78 \\
Gap 3 & & \\
Role stress & & 0.73 \\
Impersonal teamwork & TEAM1, TEAM2, TEAM5 & 0.80 \\
Personal teamwork & TEAM3, TEAM4 & 0.75 \\
Technology/job fit & TECH1 & Not applicable \\
& & (measured by \\
Perceived control & PCONT1, PCONT2, PCONT4 & 0.56 \\
\hline & &
\end{tabular}

\begin{tabular}{|c|c|c|}
\hline & Factor 1 & Factor2 \\
\hline & $\begin{array}{l}\text { Human } \\
\text { interaction }\end{array}$ & Tangibles \\
\hline EX1 & 0.05 & 0.55 \\
\hline EX2 & -0.08 & 0.66 \\
\hline EX3 & 0.01 & 0.68 \\
\hline EX4 & 0.08 & 0.52 \\
\hline EX5 & 0.65 & -0.08 \\
\hline EX6 & 0.72 & -0.12 \\
\hline EX7 & 0.77 & -0.16 \\
\hline EX8 & 0.64 & 0.05 \\
\hline EX9 & 0.80 & -0.06 \\
\hline EX10 & a.77 & -0.05 \\
\hline EX11 & 0.75 & 0.06 \\
\hline EX12 & 0.74 & -0.06 \\
\hline EX13 & 0.58 & 0.15 \\
\hline EX14 & 0.73 & 0.05 \\
\hline EX15 & 0.61 & 0.23 \\
\hline EX16 & 0.78 & -0.11 \\
\hline EX17 & 0.73 & 0.02 \\
\hline EX18 & 0.67 & 0.04 \\
\hline EX19 & a.53 & 0.09 \\
\hline EX20 & 0.55 & 0.11 \\
\hline EX21 & 0.69 & 0.04 \\
\hline $\operatorname{EX22}$ & 0.66 & 0.08 \\
\hline
\end{tabular}

The resulting rotated factor loadings shown in Table 7 reveal that gaps 2 and 3 are indeed separate constructs and that the measuring items demonstrate sufficient discrimant validity.

The internal consistency of the two instruments measuring gaps 2 and 3 revealed Cronbach alpha coefficients of 0.81 and 0.90 respectively. Items $\mathrm{G} 21, \mathrm{G} 22, \mathrm{G} 23, \mathrm{G} 24$ and G25 were regarded as measurements of gap 2 while G31, G32, G33, G34 and G35 were utilized as measurements of gap 3 .

\begin{tabular}{|c|c|c|}
\hline & Gap 3 & Gap 2 \\
\hline$\overline{G 21}$ & 0.06 & 0.44 \\
\hline G22 & 0.11 & 0.60 \\
\hline G23 & -0.17 & 0.88 \\
\hline G24 & 0.05 & 0.66 \\
\hline G25 & 0.12 & 0.68 \\
\hline G31 & 0.57 & 0.23 \\
\hline G32 & 0.79 & 0.01 \\
\hline G33 & 0.81 & 0.01 \\
\hline G34 & 0.77 & 0.01 \\
\hline G35 & 0.87 & -0.03 \\
\hline
\end{tabular}




\section{Reliability and exploratory factor analysis for gap 5}

The Cronbach alpha for the SERVQUAL instrument measuring consumer expectations and perceptions of actual service quality, and the difference scores were 0.92, 0.97 and 0.95 respectively. Five, four, three and two factor solutions for the items measuring gap 5 were considered. The most interpretable of these were the two factor solution shown in Table 8. The first factor was termed 'tangibles' and the second 'human interaction'. These factors are similar to those obtained for gap 1.

\section{Structural equation assessment}

Structural equation modelling represents significant improvements over conventional analytical tools for testing relationships among unobservable variables such as the theoretical constructs identified in Figure 1. The measurement model enables the specification of manifest variables to latent constructs. The structural equation model specifies the relationships among latent constructs. It also provides the ability to assess the goodness-of-fit for the whole model as well as an estimation of the different parameters and test for each hypothesized relationship. The results of the second stage of the data is summarized in Table 9. The table reflects the latent and manifest variables and alpha scores after the elimination of variables with low alpha coefficients.

Slightly modified versions of the empirical factor structures for the antecedents (Table 5) and gaps 1, 2, 3 and 5 (Table 9)

\begin{tabular}{|c|c|c|}
\hline & Factor 1 & Factor 2 \\
\hline & $\begin{array}{c}\text { Human } \\
\text { interaction }\end{array}$ & Tangibles \\
\hline PERMEX1 & -0.04 & 0.51 \\
\hline PERMEX2 & -0.10 & 0.76 \\
\hline PERMEX3 & 0.12 & 0.78 \\
\hline PERMEX4 & 0.15 & 0.63 \\
\hline PERMEX5 & 0.76 & -0.07 \\
\hline PERMEX6 & 0.86 & -0.11 \\
\hline PERMEX7 & 0.85 & -0.12 \\
\hline PERMEX8 & 0.60 & 0.11 \\
\hline PERMEX9 & 0.81 & -0.01 \\
\hline PERMEX10 & 0.88 & -0.04 \\
\hline PERMEX11 & 0.90 & -0.02 \\
\hline PERMEX12 & 0.88 & -0.11 \\
\hline PERMEX13 & 0.86 & -0.02 \\
\hline PERMEX14 & 0.83 & -0.05 \\
\hline PERMEX15 & 0.85 & -0.02 \\
\hline PERMEX16 & 0.76 & -0.06 \\
\hline PERMEX17 & 0.84 & 0.02 \\
\hline PERMEX18 & 0.80 & 0.05 \\
\hline PERMEX19 & 0.72 & 0.11 \\
\hline PERMEX20 & 0.59 & 0.13 \\
\hline PERMEX21 & 0.81 & 0.08 \\
\hline PERMEX22 & 0.75 & 0.08 \\
\hline
\end{tabular}

were incorporated in the causal model to be fitted to the data. This model is presented in Figure 2 by means of a path diagram. The modifications to the existing factor structures are the following:

- Gap 2 is measured by two manifest variables: GAP2AVI (the mean of G21, G22, G23) and GAP2AV2 (the mean of G24 and G25).

- Gap 3 is measured by two manifest variables: GAP3AVI (the mean of G31, G32 and G33) and GAP3AV2 (the mean of G34 and G35).

- Role stress is measured by two manifest variables RA (the mean of RA1 and RA2) and RC (the mean of RC3 and RC4).

- Gap 1 is measured by GAP1TANG (the mean of the four tangible items) and by GAP1HUMI (the mean of the reliability, the responsiveness, the assurance and the empathy items).

- Gap 5 is measured by the manifest variables GAPSTANG (the mean of the four tangible items) and GAP5HUM (the mean of the reliability, the responsiveness, the assurance and the empathy items).

\section{Amonded service quality model}

To evaluate the structural relationships in the extended service quality model, the model in Figure 1 would under perfect conditions be fitted as stated to a structural equation model for an assessment of the soundness of the model. Due to the low alpha coefficients and some items failing to load on the hypothesized constructs, the revised constructs as refined by the exploratory factor and internal consistency analyses were used as input to the structural equation model. The revised model in Figure 2 was fitted to the sample correlation matrix by using the computer programme RAMONA (Browne \& Mels, 1990). The empirical results reveal that not one of the antecedents of gap 1 or gap 3 have a significant influence on the two latent variables (gaps 1 and 3) as hypothesized by Parasuraman, Berry \& Zeithaml (1990).

Gap 2, on the other hand, is significantly influenced by Goal setting $(0.702 ; p<0.01)$ and Perceptions of infeasibility $(0.372 ; p<0.01)$.

Figure 2 also shows that only gap 1 (the marketing information gap) causes gap 5. This implies that a poor understanding of consumers' service quality expectations will contribute significantly to the discrepancies which lead to gap 5 . Neither gap 2 nor gap 3 can be described as having a significant influence on the discrepancy between the service quality customers expect and the actual service they receive.

$\begin{aligned} & \text { Table } 9 \\
& 5\end{aligned}$
\begin{tabular}{lll}
\hline Latent variables & Manifest variablesfitems & Alpha \\
\hline Gap 1 & Tangibles: EX1-EX4 \\
& Human interaction: EX5-EX22 & 0.90 \\
Gap 2 & G21-G25 & 0.80 \\
Gep 3 & G21-G25 & 0.89 \\
Gap 5 & Tangibles: PERMEX1-PERMEX4 \\
& Human interaction: PERMEX5-PERMEX22 & 0.95 \\
\hline
\end{tabular}




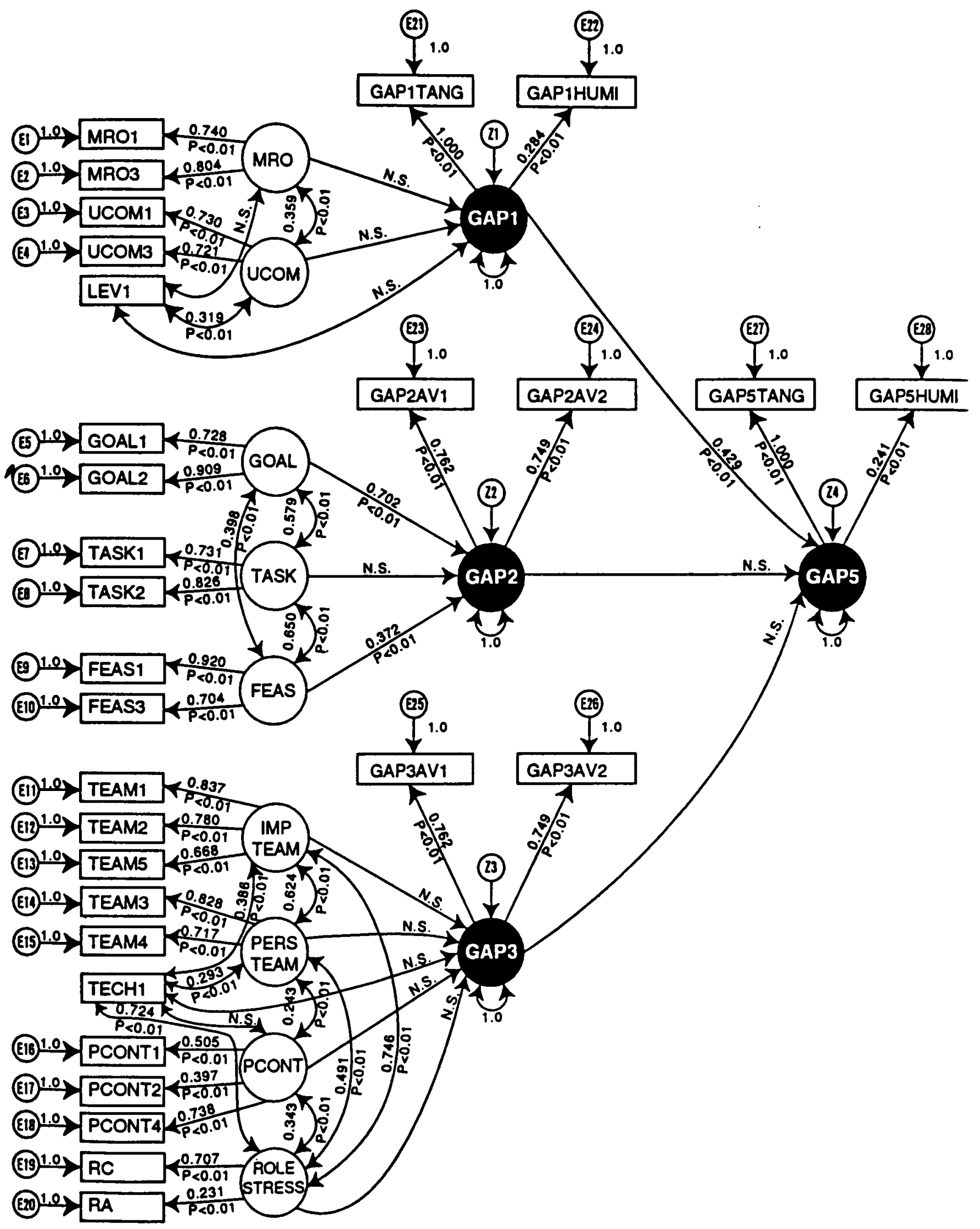

Figure 2 Model based on refined scales and exploratory factor structures

These findings differ somewhat from those reported by Parasuraman, Berry \& Zeithaml (1990: 29-32). Although they also found that gaps $1-4$ '... are only weakly associated with gap 5 ...', the correlation of gap 5 was actually negative $(-0.13)$, while the highest correlation was in respect of gap 3 $(0.25)$, followed by gap $4(0.21)$, and gap $2(0.13)$. Their re- sults indicate that gaps $1-4$ account for a negligible amount of the variance in gap 5 with none of the regression coefficients statistically significant.

The measures of fit of the model depicted in Figure 2 are listed in Table 10 and suggest that the model provides a poor fit to the data. More specifically, the Root Mean Square Error 


\begin{tabular}{|c|c|}
\hline Sample discrepancy function value & 5.02 \\
\hline \multicolumn{2}{|l|}{ Population discrepancy function value, FO } \\
\hline Bias adjusted point estimate & 2.61 \\
\hline $90 \%$ confidence interval & $(2.13 ; 3.15)$ \\
\hline \multicolumn{2}{|l|}{ Root mean square error of approstanation } \\
\hline Point estimate & 0.08 \\
\hline $90 \%$ confidence interval & $(0.07 ; 0.09)$ \\
\hline \multicolumn{2}{|l|}{ Expected cross-validation index } \\
\hline Point estimate (modified AIC) & 6.14 \\
\hline $90 \%$ confidence interval & $(5.65 ; 6.67)$ \\
\hline CVI (modified AIC) for the saturated model & 5.92 \\
\hline \multicolumn{2}{|l|}{ Chi-square goodness- $\alpha$-fit test } \\
\hline Value of test statistic & 788.12 \\
\hline Degrees of freedom $=377$ & 377 \\
\hline \multicolumn{2}{|l|}{ Exceedance probabilities } \\
\hline HO: perfect fit (RMSEA $=0.0$ ) & 0.00 \\
\hline H0: close fit (RMSEA $=0.05)$ & 0.00 \\
\hline Effective number of parameters & 88 \\
\hline
\end{tabular}

of Approxiamtion (RMSEA) value exceeds 0.08 which indicates a poor fit (Browne \& Mels, 1990; Steiger \& Lind, 1980). This finding is supported by the fact that the modified AIC for the model exceeds that of the saturated model.

\section{Path analysis results}

Due to the poor fit of the original model depicted in Figure 2 it was deemed necessary to consider alternative service quality models by modifying the existing model in an effort to obtain a more suitable service quality model. As suggested by Kerlinger \& Pedhazur (1973: 318) an attempt was made to improve the fit of the model to the data by deleting inappropriate paths from the original model.

Various options were considered. One alternative was to remove all the antecedents of both gaps 1 and 3. This alteration actually resulted in an even poorer fit. A second alternative was to remove tangibles as measurements of both gaps 1 and 5. This minor modification led to a model providing a reasonable fit to the data (compared to the previous poor fit). The corresponding results also suggested that gap 3 may be removed from the model. This modification led to the model depicted in Figure 3, which was fitted to the correlation matrix by using the computer programme RAMONA (Browne \& Mels, 1990). The corresponding maximum likelihood estimates are listed in Figure 3 while the measures of fit are given in Table 11. Of all the alternative models considered, the model in Figure 3 yielded the smallest RMSEA (0.076) and appears to be the most suitable service quality model for the respondents in this study.

Figure 3 shows, as was the case with the initial model, that goal setting and perception of infeasibility are the major causes of gap 2, but that gap 2 only marginally influence gap 5. Gap 1 on the other hand exerts a significant influence on gap 5. Figure 3 also shows that gap 2 does not influence gap

\begin{tabular}{|c|c|}
\hline Sample discrepancy function value & 1.7 \\
\hline \multicolumn{2}{|l|}{ Population discrepancy function value, FO } \\
\hline Bias adjusted point estimate & 0.83 \\
\hline $90 \%$ confidence interval & $(0.55 ; 1.15)$ \\
\hline \multicolumn{2}{|l|}{ Root mean square error of approximation } \\
\hline Point estimate & 0.07 \\
\hline 90\% confidence interval & $(0.06 ; 0.09)$ \\
\hline \multicolumn{2}{|l|}{ Expected cross-validation index } \\
\hline Point estimate (modified AIC) & 2.34 \\
\hline $90 \%$ confidence interval & $(2.06 ; 2.66)$ \\
\hline CVI (modified AIC) for the saturated model & 2.42 \\
\hline Test statistic & 273.34 \\
\hline \multicolumn{2}{|l|}{ Exceedance probabilities } \\
\hline H0: perfect fit (RMSEA $=0.0$ ) & 0.00 \\
\hline HO: close fit (RMSEA = 377) & 0.001 \\
\hline Degrees of freedom $=377$ & 143 \\
\hline Effective number of parameters & 47 \\
\hline
\end{tabular}

1. It is interesting to note that all three of the antecedents of gap 2 are significantly ( $<<0.01$ ) correlated.

The fact that the removal of tangibles, as measures of both gaps 1 and 5, significantly improved the fit of the service quality model places a question mark over the importance of tangibles in service quality perceptions and evaluations

\section{Implications}

The empirical results reported in this study suggest that considerable research is still required to enhance our understanding of the factors influencing service quality. Three concerns are the improvement of the psychometric capabilities of the scales used in this study, the search for unspecified constructs and antecedents which may influence individual gaps, and the unbundling of the internal gaps.

Of the $\mathbf{5 0}$ antecedents operationalized by Parasuraman, Berry \& Zeithaml (1990) only 20 are significantly related to the hypothesized constructs as depicted in Figure 2 for this sample. Only four antecedents measuring the constructs goal setting and perception of infeasibility are correlated with gap 2 , but with no causal link to gap 5 . All the remaining constructs as listed in Table 1 exert no influence on gap 5. At best a limited range of the antecedents can be regarded as measurements of the manifest variables, but it offers little enlightment if the manifest variables do not influence the latent variables. Gap 1 was the only latent variable significantly influencing gap 5.

The significance of the marketing information gap (gap 1) highlights the need to explore the impact of information/ knowledge utilization in organizations and its potential for understanding relationships between marketing and other departments. Utilizing market intelligence and marketing research information are emerging as a critical requirement for the firm to become market oriented (Kohli \& Jaworski, 1990). Market orientation in turn is essential to lead the organization to greater levels of customer satisfaction and 


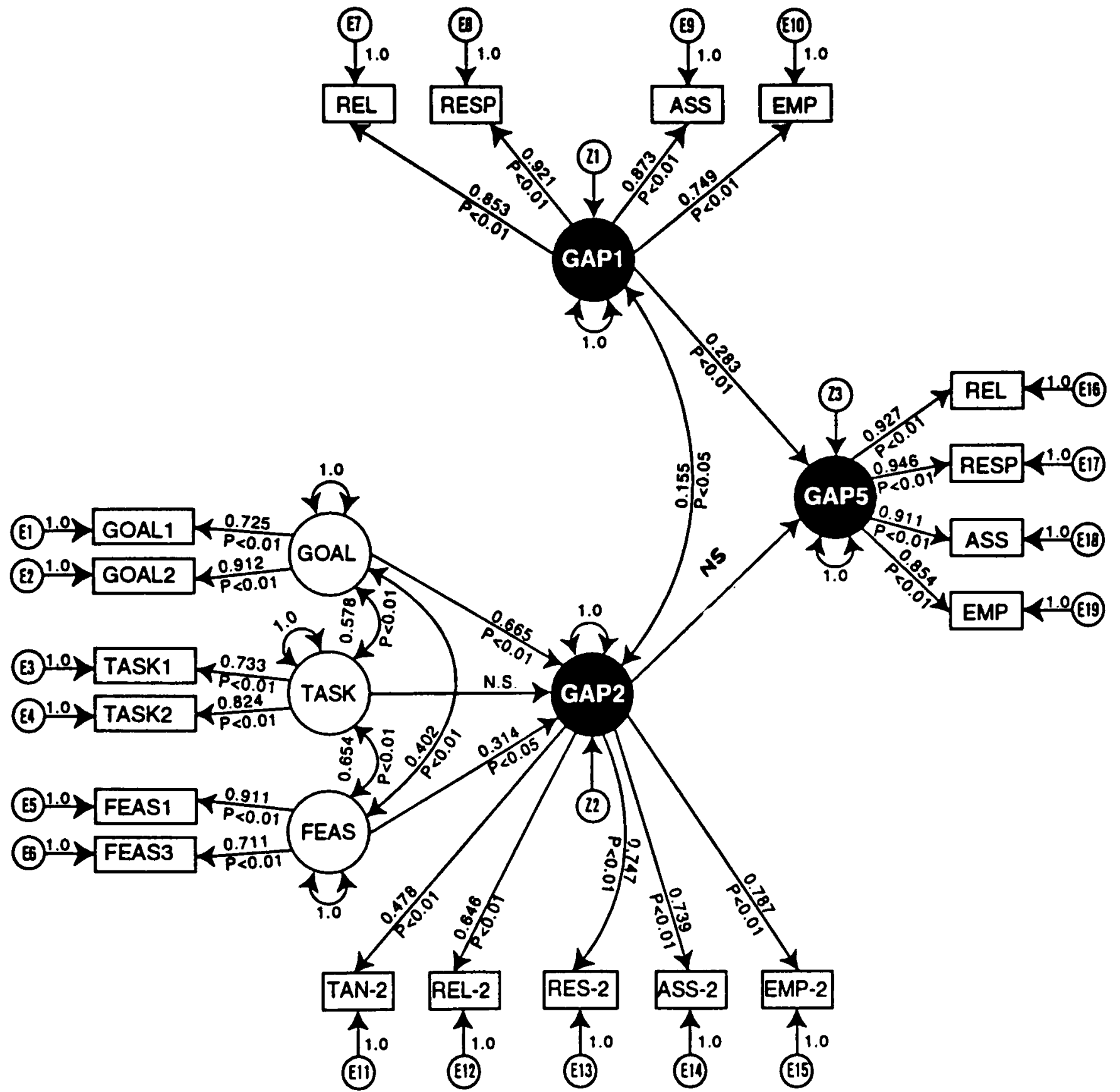

Figure 3 Path analysis results for the empirical service quality model

organizational commitment of employees (Jaworski \& Kohli, 1993). This implies that relevant market information must be produced and disseminated to various departments and managers that is specific and action-oriented outside the traditional marketing department (Menon \& Varadarajan, 1992). The more information intensive the organization becomes the more the marketing department will be required to get involved in activities not traditionally associated with marketing (Glazer, 1991: 7-8). It stands to reason that a deeper understanding of knowledge utilization could have a profound impact on our ability to deal with the issues relating to gaps 2, 3 and 4. To accomplish this objective, the development of a valid measure of knowledge utilization requires refinement and further empirical testing far beyond the limited scope the current antecedents offered by the extended service quality model.
As suggested by Parasuraman, Berry \& Zeithaml (1990: 40), it may be fruitful if future studies are initially limited to individual gaps rather than the entire model, as such a focussed approach is likely to provide a richer insight than broadly based studies.

\section{Recommendations for future research}

The measuring scales proposed by Zeithaml, Berry \& Parasuraman (1990) represent composite scores as defined by the respondents' scores on these measures, which provides an estimate of the corresponding construct. The computation of a composite score is only meaningful if each of the measures is unidimensional. Unidimensional means that a set of items forming a scale all measure just one common underlying theme (Hattie, 1985). The implications are that any scale development process must include an assessment of whether 
multiple measures that define a scale can be acceptably regarded as alternative indicators of the same construct. To satisfy the requirements of unidimensionality, scale development should incorporate confirmatory factor analysis as outlined by Jöreskorg \& Sörbom (1984). The issues are summerized by Gerbing \& Anderson,

'The key aspect of this uprated paradigm is that confirmatory factor analysis affords a stricter interpretation of unidimensionality than can be provided by more traditional methods such as coefficient alpha, item-total correlations, and exploratory factor analysis and thus generally will provide different conclusions about the acceptability of a scale' (1988).

\section{Conclusion}

Future studies should attempt to develop unidimensional scales by focussing on each internal gap individually. Once improved scales are developed, the extended service quality model could be reassessed to determine if there are any relationships among latent variables as currently hypothesized. Current evidence suggests that the internal gaps offer limited causal relationship with the service quality gap.

\section{References}

Babakus, E. \& Boller, G.W. 1992. An empirical assessment of the SERVQUAL scale, Journal of Business Research, 24(3):253-268.

Bollen, K.A. 1989. Structural equations with latent variables. New York: Wiley.

Bolten, R. \& Drew, J.H. 1991. A multistage model of customers' assessment of service quality and value, Journal of Consumer Research, 17: 375-384.

Bowen, D.E. \& Schneider, B. 1988. Services marketing and management: implications for organisational behavior. In Staw, B.M. \& Cummings, L.L. eds. Research in organizational behavior, vol. 10. Greenwich CT: JAI Press Inc.

Brown, TJ., Churchill, G.A. \& Peter, J.P. 1993. Improving the measurement of service quality, Journal of Retailing, 69(1): 127-140.

Browne, M.W. \& Mels, G. 1990. RAMONA PC user's guide. Technical report. Pretoria: Human Sciences Research Council.

Carman, J.M. 1990. Consumer perceptions of service quality: an assessment of the SERVQUAL dimensions, Journal of Retailing, 66:33-55.

Crompton, J.L. \& Mackay, K.J. 1989. Users' perceptions of the relative importance of service quality dimensions in selected public recreation programs, Leisure Sciences, 11: 367-375.

Cronbach, L.J. 1951. Coefficient alpha and the internal structure of tests, Psychometrika, 16(3): 297-333.

Cronin, J.J. \& Taylor, S.A. 1992. Measuring service quality: a re-examination and extension, Journal of marketing, 56(3):55-68.

Finn, D.W. \& Lamb, C.W. 1991. An evaluation of the SERVQUAL scales in a retail setting, Advances in Consumer Research, 18: 483-490.

Frane, J.R. \& Jennrich, P.F. 1990. 4M-factor analysis. In William, J. Dixon et al. eds. BMDP Statistical Software Manual, vol. 1. Berkeley: Univerty of California Press.

Gerbing, D.W. \& Anderson, J.C. 1988. An uprated paradigm for scale development incorporating unidimesionality and its assess. ment, Journal of Marketing Research, XXV:186-192.

Glazer, R. 1991. Marketing in an information-intensive environment: strategic implications of knowledge as an asset, Journal of Marketing, 55: 1-19.

Gronrös, C. 1984. A service quality model and its marketing implications, European Journal of Marketing, 18(4): 36-44.
Hattie, J. 1985. Methodology review: assessing unidimensionality of tests and items, Applied Psychological Measurement, 9: 139-164.

Heskett, J.L. 1987. Lessons in the service sector, Harvard Business Review, 87: 118-126.

Jaworski, J.J. \& Kohli, A.J. 1993. Market orientation: antecedents and consequences, Journal of Marketing, 57: 53-70.

Jennrich, R.I. \& Sampson, P.F. 1966. Rotation for simple loadings, Psychometrika, 31: 34-42

Johnson, L.L., Dotson, M.J. \& Dunlap, B.J. 1988. Service quality determinants and effectiveness in the real estate brokerage industry, Journal of Real Estate Research, 3: 21-36.

Jorreskog, K.G. \& Sörbom, D. 198. Lisrel VI: analysis of the structural relationships by the method of maximum likelihood. Chicago: National Educational Resources, Inc.

Kerlinger, F.N. \& Pedhazur, E.J. 1973. Multiple regression in behav. ioural research. New York: Reinhart and Winston.

Kohli, A.J. \& Jaworski, J.J. 1990. Market orientation: the construct, research propositions, and managerial implications, Joumal of Marketing, 54: 1-18.

Lehtinen, U. \& Lehtinen, J.R. 1982. Service quality: a study of quality dimensions. Unpublished working paper. Helsinki: Service Management Institute, Finland, $O Y$.

Lewis, R.C. \& Booms, B.H. 1983. The marketing aspects of service quality. In Berry, L.L., Shostack, G. \& Upah, G. eds. Emerging perspectives on services marketing. Chicago: American Marketing Association, pp.99-107.

Menon, A. \& Varadarajan, P.R. 1992. A model of marketing knowledge use within furms, Journal of Marketing, 4: 53-71.

Nunnally, J.C. 1978. Psychometric theory, 2nd ed. New York: McGraw-Hill.

Parasuraman, A., Berry, L.L. \& Zeithaml, V.A. 1990. An empirical examination of relationships in an extended service quality model. Cambridge, MA: Marketing Science Institute.

Parasuraman, A., Berry, L.L. \& Zeithaml, V.A. 1991. Refinement and reassessment of the SERVQUAL scale, Journal of Retailing, 67(4): 420-450.

Parasuraman, A., Berry, L.L. \& Zeithaml, V.A. 1993. More on improving service quality measurement, Journal of Retailing, $69(1)$ : 140-147.

Parasuraman, A., Zeithaml, V.A. \& Berry, L.L. 1985. A conceptual model of service quality and its implications for future research, Journal of Marketing, 49: 41-50

Parasuraman, A., Zeithaml, V.A. \& Berry, L.L. 1988. SERVQUAL: a multiple-item scale for measuring consumer perceptions of service quality, Journal of Retailing, 64: 12-30.

Ramaswani, S.N., Agarwal, S. \& Bhargava, M. 1993. Work alienation of marketing employees: influence of task, supervisory, and organisational structure factors, Journal of the Academy of Mar. keting Science, 21(3): 179-193.

Steiger, J.H. \& Lind, J. 1980. Statistically based tests for the number of common factors. Annual Meeting of the Psychometric Society, Iowa City, IA.

Teas, R.K. 1993. Expectations, performance evaluation and consumers; perceptions of quality, Journal of Marketing, 57(4): 18-34.

Woodside, A.G., Frey, L.L. \& Daly, R.T. 1989. Linking service quality, customer satisfaction, and behavioural intention, Journal of Heath Care Marketing, 9: 5-17.

Zeithaml, V.A., Berry, L.L. \& Parasuraman, A. 1988. Communication and control processes in the delivery of service quality, Journal of Marketing, 52: 34-48.

Zeithaml, V.A., Berry, L.L. \& Parasuraman, A. 1993. The nature and determinants of customer expectations of service, Journal of the Academy of Marketing Science, 21(1): 1-12.

Zeithaml, V.A., Parasuraman, A. \& Berry, L.L. 1990. Delivering quality service balancing customer perceptions and expectations. New York: The Free Press. 